\title{
Flexural Behaviour of Reinforced Concrete Beam with Hollow Core at Various Depth
}

\author{
Nibin Varghese ${ }^{1}$, Anup Joy ${ }^{2}$ \\ ${ }^{1}$ PG Scholar, Structural Engineering, SBCE. \\ ${ }^{2}$ Assistant Professor, Department of Civil Engineering, SBCE
}

\begin{abstract}
Nowadays research efforts are continuously looking for new, better and efficient construction material and method.In recent days the problem faced by the construction industry is acute shortage of raw materials. We have responsibility to reduce the effect of the application of concrete materials to environmental impact. The concrete should be used as efficiently as much as possible.In case of simply supported reinforced concrete beam, the region below neutral axis is in tension and above neutral axis is in compression. As concrete is weak in taking tension, steel reinforcements are provided in this zone. The concrete below the neutral axis act as a stress transfer medium between the compression and tension zone. Partial replacement of the concrete below the neutral axis is an idea that can create reduction in weight and savings in materials. This research focuses on structural material optimization by introducing hollow core using PVC pipe in tension zone of RC beams. By material optimization, we can reduce the dead loads which contribute to seismic effect in high rise structures. This paper presents details of the studies carried out on flexural behaviour of Hollow Core Sandwich RC Beams with different core depths. The experimental program consists of casting and testing of RC beams of size 2000mm x200mm $x 300 \mathrm{~mm}$ with and without hollow core in tension zone. To study the flexural behaviour, all beams are tested by four point loading. The performance of Hollow Core Sandwich Beams under flexure shows better when compared with conventional solid beams.
\end{abstract}

Keywords: Neutral Axis, Hollow Reinforced Concrete Beam, Light-Weight Material, Flexural behaviour etc

\section{Introduction}

Concrete materials are still a dominant material for construction due to its advantages such as workability, low cost and fire resistance as well as its low maintenance cost. It is formed from a hardened mixture of cement, fine aggregate, coarse aggregate, water and some admixture. Massive exploration of the natural resources for producing concrete affect to the environment condition and global warning. We have responsibility to reduce the effect of the application of concrete materials to environmental impact. The concrete should be used as efficient as possible. Nowadays researches efforts are continuously looking for new, better and efficient construction method. Various theories related to the analysis of structural elements reduced the self-weight of element for a given load- carrying capacity. Structural material optimization can reduce the dead load which reduce the contribution of seismic effect in high rise structures and also very good at the vibration dampers and heat isolation.

According to the natural behaviour of the concrete, it is strong in compression and weak in tension. Our assumption to design the R.C beams is the contribution of tensile stress of the concrete is neglected. The flexural capacity (MR) of the beam is influenced only by compression stresses of the concrete and the tensile stress of the steel reinforcement. Efficient use the concrete materials can be done byreplacing the concrete in and near the neutral axis. However, in RC beams strength of concrete lying in and near the neutral axis is not fully utilized. So this un-utilized concrete is removed by placing a PVC pipe instead, hence making the beam hollow at the neutral axis. This is an alternative to reduce the use of concrete. The concrete just above neutral axis is less stressed where as the concrete below the neutral axis serves as a shear transmitting media. The bond between PVC pipe and concrete layers at the pipe concrete interface should essentially be very good. It should be ensured that no slip will occur between the two layers. Experimental work is carried on the reinforced concrete beams with hollow neutral axis, with the view that the stresses in the beams are maximum at the top and bottom and zero at the neutral axis. So a cheap and light material can be used near the neutral zone. Sustainability can be achieved by replacing the partially used concrete. By saving concrete, we can save cement, which reduces the greenhouse gases emissions. So it is considered as environment friendly.

According to various literature review it is observed that there is a problem related to the depth and continuity of hollow core. So this paper is an attempt to study flexural behaviour of reinforced concrete beam with hollow core at various depths under four point loading. This aims to obtain an efficient and optimum depth and pattern for the provision of hollow core.

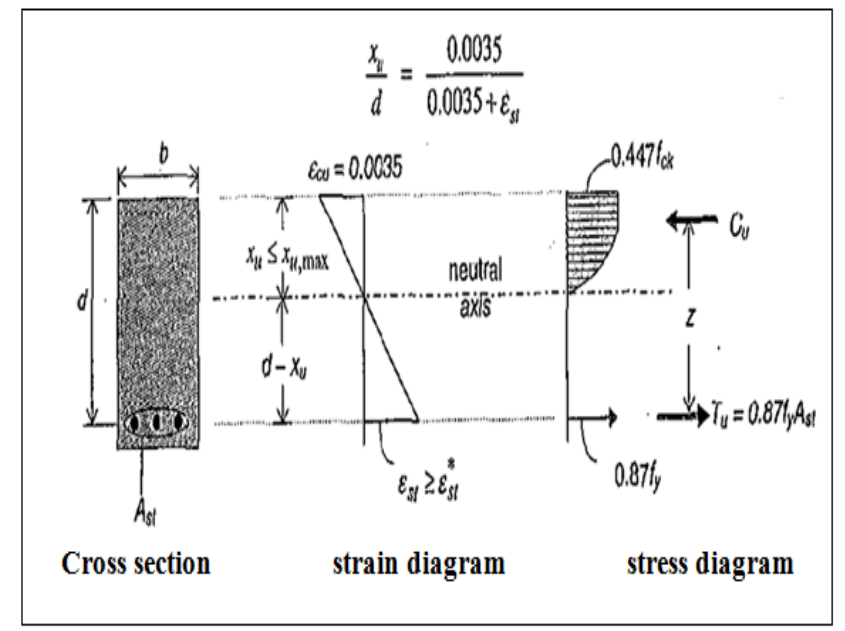

Figure 1: Stress and strain block for a singly reinforced beam 


\section{International Journal of Science and Research (IJSR) \\ ISSN (Online): 2319-7064}

Index Copernicus Value (2013): 6.14 | Impact Factor (2015): 6.391

\section{Literature Survey}

[1] S.Manikandan, S.Dharmar, S. Robertravi (2015)

S Manikandan and two others conducted an experimental study on flexural behaviour of reinforced concrete hollow core sandwich beams. This paper presents details of the studies carried out on flexural behavior of Hollow Core Sandwich RC Beams with different core shapes. The experimental program consists of casting and testing of RC beams of size $1500 \mathrm{~mm} \times 150 \mathrm{~mm} \times 200 \mathrm{~mm}$ with and without hollow core in tension zone. To study the flexural behavior, all beams are tested after 28 days curing by applying loads at $1 / 3$ rd points. The performance of Hollow Core Sandwich Beams under flexure is similar when compared with conventional solid beams.

\section{[2] Jain Joy, Rajesh Rajeev (2014)}

They conducted an experimental study on Effect of Reinforced Concrete Beam with Hollow Neutral Axis. In this investigative study they developed a Reinforced Concrete Beam with hollow neutral axis which may replace the position of reinforced concrete beam in near future. In $\mathrm{RC}$ beams strength of concrete lying in and near the neutral axis is not fully utilized. So this un-utilized concrete is removed by replacing with any light-weight material. The material incorporated in the concrete beam is PVC pipe, which occupy the concrete volume in the neutral axis, where the compression and tension is zero thereby making the beam hollow. The properties of PVC is not been used since it is used only as a filler material in concrete. Specimens of solid RC beams and Hollow RC beams are cast and tested for four point flexure. Then the results are compared and the effects are studied. The self-weight of this developed RC beams are reduced with the decrease in concrete volume hence proving the beams to be economical. Experimental validation is carried out analytically with ANSYS 12.1 software.

\section{[3] Rakesh Patel, S.K. Dubey, K.K. Pathak (2014)}

They conducted an analatical study on infilled beams using method of initial functions and comparison with FEM. This paper presents a study carried out on reinforced concrete infilled beams. In reinforced concrete beams, less stressed concrete near neutral axis can be replaced by some light weight material like bricks to reduce the weight of the structure and also achieve the economy. Infilled zone is obtained with the help of stress block diagram, used for limit state design of reinforced concrete beams as per IS 456. Method of initial functions is used for the analysis of infilled reinforced concrete composite beams. The method of initial function (MIF) is an analytical method of elasticity theory. The results obtained by MIF are compared with those predicting by Finite Element Method (FEM) based software ANSYS, and it is observed that they are comparable.

[4] B S Karthik, Dr.H.Eramma and Madhukaran (2014) They conducted an experimental study on behavior of concrete with grade variation in tension and compression zones of RCC beams. In a normal beam (simply supported) two zones generally arise, viz. compression zone at top and tension zone at bottom. As concrete is weak in tension, steel is introduced in the tension zone to take the tension, but as strength of concrete is ignored in tension zone with respect to compression zone. So logically no concrete is required in tension side. But this concrete needs to be provided on tension side to act as strain transferring media to steel and may be called as 'sacrificial concrete'. Due to this concrete has no tensions more than strain transferring, they changed the grade of concrete which is used in upper zone and lower zone. In his study a concrete grade reductioning in tension zone for RCC beams is done to reduce construction cost.

\section{Objective of the Work}

The objectives is to conduct a pilot study on introducing a new method of replacing some amount of the concrete below neutral axis by creating air voids using PVC pipes without affecting the geometry of the section.

\section{Methodology}

The methodology of the work consist of

1) Selection of grade of concrete; M30.

2) Mix design of M30 grade concrete.

3) Casting beam specimens of normal RC beams and partialy replaced beam specimens.

4) Conducting four point load test using $100 \mathrm{~T}$ loading frame.

5) Study the effect and documentation

\section{Material Test}

Table 1: Material Testing Results

\begin{tabular}{|c|c|c|c|}
\hline Test & Material & Equipment Used & $\begin{array}{c}\text { Values } \\
\text { Obtained }\end{array}$ \\
\hline $\begin{array}{c}\text { Specific } \\
\text { Gravity }\end{array}$ & $\begin{array}{c}\text { Ramco cement } \\
\text { (OPC 43 grade) }\end{array}$ & Le Chatelier flask & 3.2 \\
\hline $\begin{array}{c}\text { Specific } \\
\text { Gravity }\end{array}$ & $\begin{array}{c}\text { Fine } \\
\text { Aggregates }\end{array}$ & pycnometer & 2.61 \\
\hline $\begin{array}{c}\text { Specific } \\
\text { Gravity }\end{array}$ & $\begin{array}{c}\text { Coarse } \\
\text { Aggregates }\end{array}$ & Wire basket & 2.77 \\
\hline $\begin{array}{c}\text { Water } \\
\text { absorption }\end{array}$ & $\begin{array}{c}\text { Fine } \\
\text { Aggregates }\end{array}$ & Vessel & $1.02 \%$ \\
\hline $\begin{array}{c}\text { Water } \\
\text { absorption }\end{array}$ & $\begin{array}{c}\text { Coarse } \\
\text { Aggregates }\end{array}$ & vessel & $0.6 \%$ \\
\hline vorkability & M30 concrete & lump cone apparatus & $110 \mathrm{~mm}$ \\
\hline
\end{tabular}

\section{Mix Design}

Table 2: M30 Mix Proportioning

\begin{tabular}{|c|c|}
\hline Cement $(\mathrm{Kg} / \mathrm{m} 3)$ & 438 \\
\hline Fine aggregate $(\mathrm{Kg} / \mathrm{m} 3)$ & 695 \\
\hline Coarse aggregate $(\mathrm{Kg} / \mathrm{m} 3)$ & 1107 \\
\hline Water $(\mathrm{li} / \mathrm{m} 3)$ & 197 \\
\hline Water cement ratio & 0.45 \\
\hline Mix ratio $1: 1.59: 2.52: 0.45$ \\
\hline
\end{tabular}

\section{Experimental Investigation}

\section{A. Experimental Program}

The test program consists of casting and testing ten beams in the size $200 \times 300 \times 2000 \mathrm{~mm}$ out of which two are cement concrete control beams (CB), two are beams with hollow core at depth $120 \mathrm{~mm}$ from top(B1), two are beams with hollow core at depth $160 \mathrm{~mm}$ from top(B2), two are beams with hollow core at depth $200 \mathrm{~mm}$ from top(B3), and last two are beams with hollow core at depth $240 \mathrm{~mm}$ from top(B4). 


\section{International Journal of Science and Research (IJSR) \\ ISSN (Online): 2319-7064}

Index Copernicus Value (2013): 6.14 | Impact Factor (2015): 6.391

The beams designed as under reinforced section according to IS 456-2000.It is reinforced with 3-16Dia at bottom, 212Dia at top and shear reinforcementusing $8 \mathrm{~mm}$ Dia stirrups @ $150 \mathrm{~mm} \mathrm{c} / \mathrm{c}$ casting process is performed according to the basic standards and concrete treatment process is performed for 28 day. All the beam specimens were subjected to a four point bending test. Three main aspects were examined; flexural strength, center span deformation and strain behaviour of beam.

The depth of neutral axis is calculated by considering M30 grade concrete and Fe500 steel with an effective cover of $25 \mathrm{~mm}$. The section is designed as a balanced or underreinforced one, the steel also reaches yield as concrete fails. According to IS 456-2000

$$
\begin{aligned}
& \mathrm{Pt}_{\text {limit }}=41.61 \frac{\text { fck }}{f y} \frac{\text { Xumax }}{d} \\
& \mathrm{Pt}_{\text {limit }}=1.14 \% \\
& 100 \text { Ast } / \mathrm{b} * \mathrm{~d}=1.14 \% \\
& \text { Ast }=1.14 * 200 * 275 / 100 \quad \text { Ast }=627 \mathrm{~mm}^{2}
\end{aligned}
$$

Area of steel Provided $=3 *\left(\pi^{*} 16^{2} / 4\right)=603 \mathrm{~mm}^{2}$

Hence section is under reinforced

Depth of Neutral axis

$\mathrm{Xu}=0.87 * \mathrm{fy} * \mathrm{Ast} / 0.36 * \mathrm{fck} * \mathrm{~b}$

$$
\begin{aligned}
& \mathrm{Xu}=\frac{0.87 \times 500 \times 603}{0.36 \times 30 \times 200} \\
& \mathrm{Xu}=121 \mathrm{~mm}
\end{aligned}
$$

Limiting Value of the Depth of Neutral axis Xumax $=0.46 * 275=126.5 \mathrm{~mm}$

$$
\text { (Xu<Xumax) }
$$

Hence section is under reinforced

Minimum shear reinforcement

Asv $/(\mathrm{b} * \mathrm{~Sv})=0.4 /(0.87 * \mathrm{fy})$

Svprov $=150 \mathrm{~mm}$

8mm $\Phi$ bar@150 mm spacing

The zone below the neutral axis is divided into four zones and each zone is replaced with voids created by placing circular PVC pipes of diameter $50 \mathrm{~mm}$ in zigzag pattern.

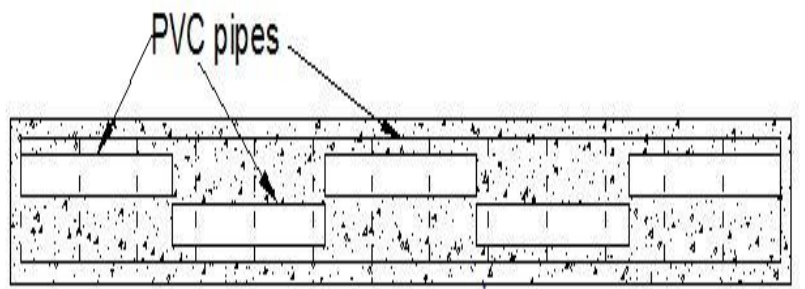

Figure 2: Schematic sectional plan of replaced specimen

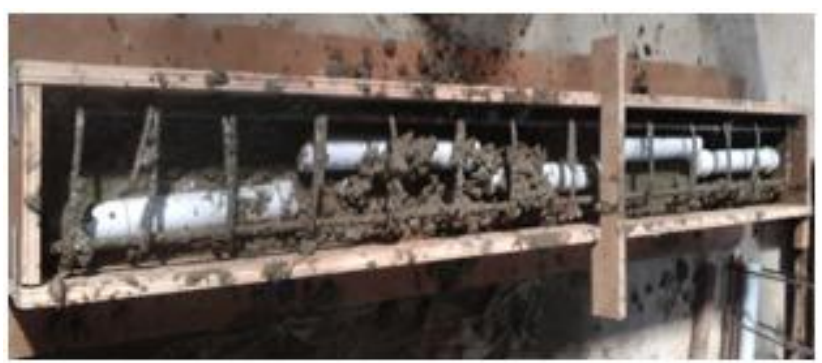

Figure 3: Casting of Replaced Beam

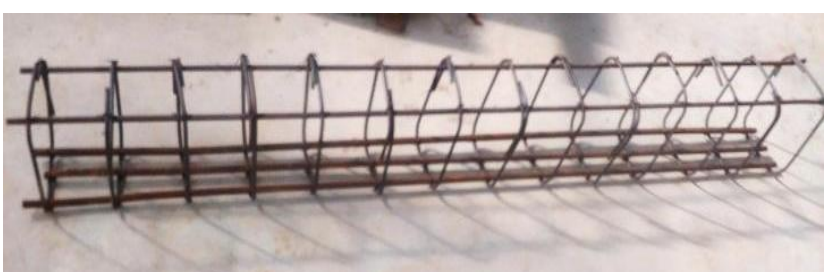

Figure 4: Reinforcement Cage for Beam Specimens

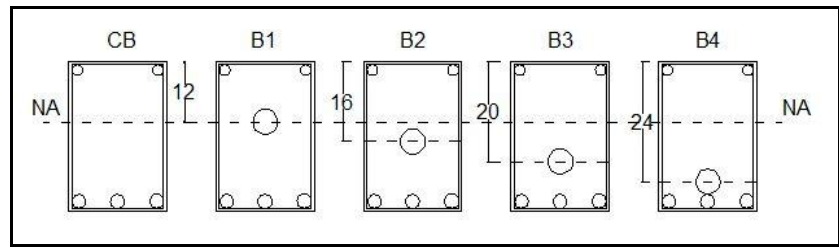

Figure 5: Schematic cross sectional view of beam specimens

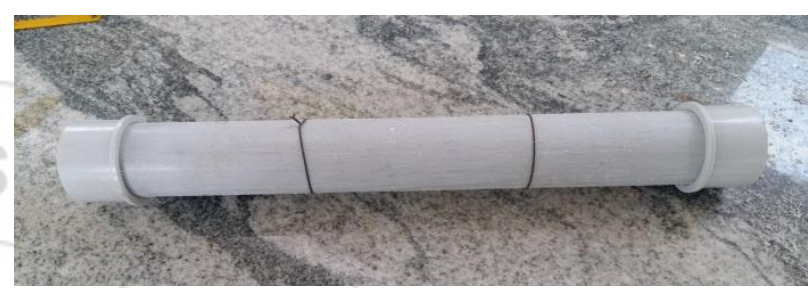

Figure 6: Circular PVC pipe used for providing hollow core

\section{B. Test Procedure}

The flexural strength of the specimens were tested using a 100t loading frame; LVDT was used to determine the deflection at the center of the beam. The effective span of the test specimen is taken as $1800 \mathrm{~mm}$ which achieved by using cast iron support. The flexural strength of the beam is found by fourpoint loading using the jack attached to the loading frame. The behaviour of beam is keenly observed from beginning to the failure. The loading was stopped when the beam was just on the verge of collapse. The first crack propagation and its development and propagation are observed keenly. The values of load applied and deflection are noted directly and further the plot of load vs. deflection is performed which is taken as the output. The load in $\mathrm{KN}$ is applied with uniformly increasing the value of the load and the deflection under the different applied loads is noted down. The applied load increased up to the breaking point or till the failure of the material

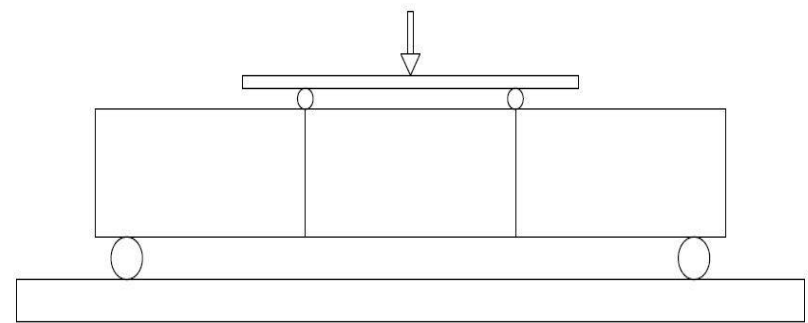

Figure 7: Schematic Test Setup 


\section{International Journal of Science and Research (IJSR)}

ISSN (Online): 2319-7064

Index Copernicus Value (2013): 6.14 | Impact Factor (2015): 6.391

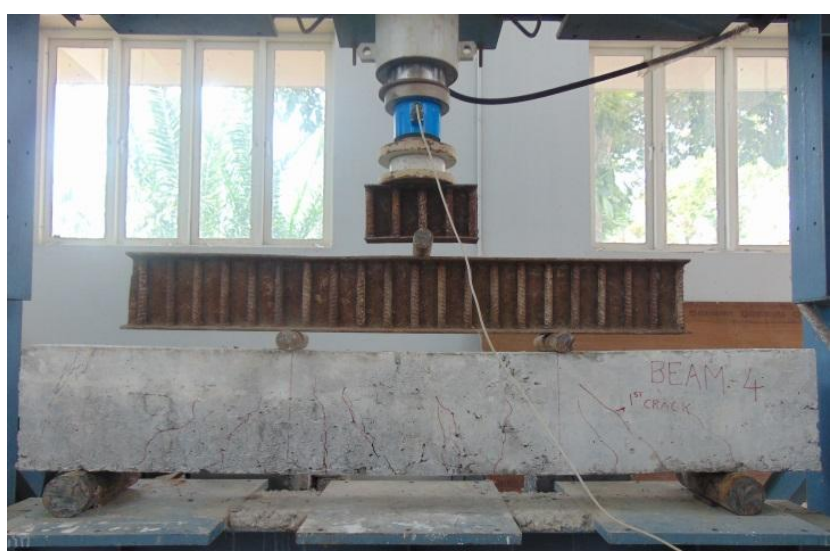

Figure 8: Experimental Setup of Beam Specimens

\section{Experimental Results and discussion}

\section{A. Load Carrying Capacity}

Ultimate strength of beams under four point test was confirmed through recording the maximum load indicated by LVDT, but the cracking load was specified with developing the first crack on the concrete. It was found that the load carrying capacity of all partially replaced beams are more than that of solid control beam section. The comparison of the results between the solid control beam and beam with replacement below the neutral axis is shown in Figure.9. The solid control beams are designated as CB, beams with hollow core at depth $120 \mathrm{~mm}$ from top as B1, beams with hollow core at depth $160 \mathrm{~mm}$ as B2, beams with hollow core at depth $200 \mathrm{~mm}$ as B3, and beams with hollow core at depth $240 \mathrm{~mm}$ as B4.

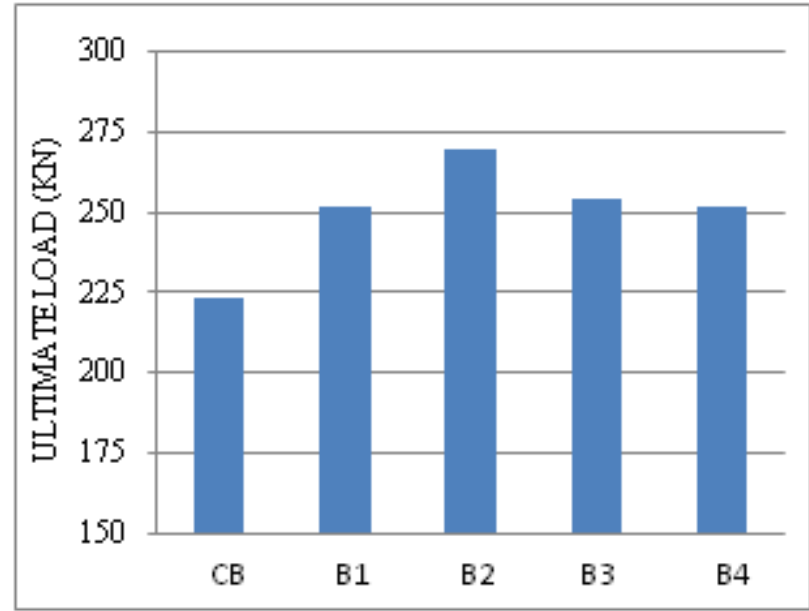

Figure 9: Ultimate Load of Beam

\section{B. Load Vs. Deflection Graph}

As the load increases the deflection of the beam begins. Load will be directly proportional to deflection. The load values and corresponding deflection of solid control beam and beam with replacement at the neutral axis upto a safe load of $200 \mathrm{kN}$ is given in Table 3.As per the test result it is observed that all partially replaced beams show less deflection than control beam at the safe load.
Table 3: Load and Deflection Values Of Beam Specimens

\begin{tabular}{|c|c|c|c|c|c|}
\hline \multirow{2}{*}{$\begin{array}{c}\text { LOAD } \\
(K N)\end{array}$} & \multicolumn{5}{|c|}{ DEFLECTION $(\mathrm{mm})$} \\
\hline & $C B$ & $B 1$ & $B 2$ & $B 3$ & $B 4$ \\
\hline 10 & 0.2 & 0.12 & 0.12 & 0.2 & 0.11 \\
\hline 20 & 0.3 & 0.27 & 0.15 & 0.45 & 0.22 \\
\hline 30 & 0.42 & 0.4 & 0.19 & 0.8 & 0.32 \\
\hline 40 & 0.54 & 0.5 & 0.25 & 0.97 & 0.4 \\
\hline 50 & 0.63 & 0.55 & 0.38 & 1.12 & 0.51 \\
\hline 60 & 0.72 & 0.7 & 0.49 & 1.27 & 0.65 \\
\hline 70 & 0.89 & 0.83 & 0.61 & 1.42 & 0.8 \\
\hline 80 & 1.1 & 0.93 & 0.73 & 1.71 & 1 \\
\hline 90 & 1.28 & 1.03 & 0.91 & 1.94 & 1.22 \\
\hline 100 & 1.53 & 1.25 & 1.13 & 2.15 & 1.39 \\
\hline 110 & 1.78 & 1.42 & 1.33 & 2.46 & 1.65 \\
\hline 120 & 2.09 & 1.62 & 1.54 & 2.61 & 1.82 \\
\hline 130 & 2.42 & 1.76 & 1.76 & 2.8 & 2.05 \\
\hline 140 & 2.82 & 1.96 & 2 & 3.03 & 2.25 \\
\hline 150 & 3.05 & 2.11 & 2.22 & 3.27 & 2.54 \\
\hline 160 & 3.4 & 2.4 & 2.46 & 3.52 & 2.76 \\
\hline 170 & 3.72 & 2.61 & 2.67 & 3.75 & 2.79 \\
\hline 180 & 4.05 & 2.86 & 2.94 & 4 & 3.18 \\
\hline 190 & 4.47 & 3.11 & 3.19 & 4.26 & 3.4 \\
\hline 200 & 4.78 & 3.25 & 3.43 & 4.51 & 3.71 \\
\hline & & & & & \\
\hline
\end{tabular}

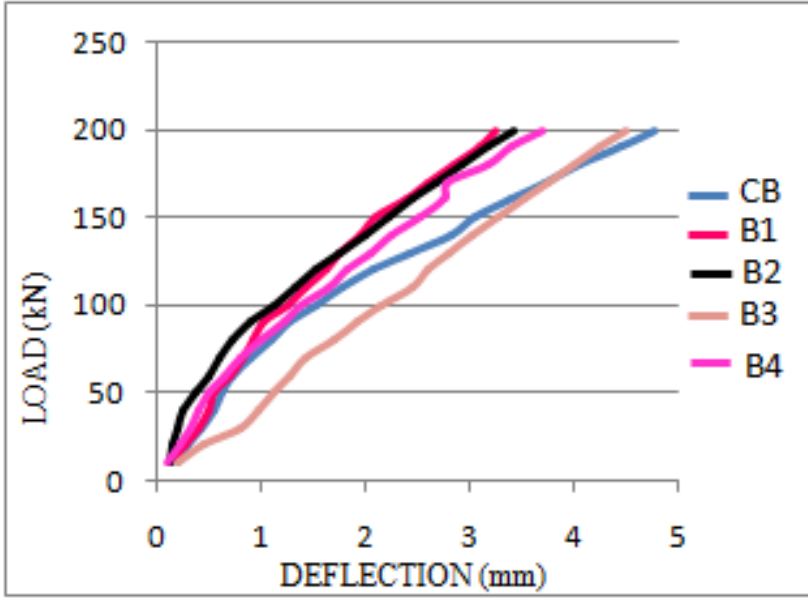

Figure 10: Load vs. Deflection Graph upto $200 \mathrm{kN}$

\section{Ultimate Load Vs. Depth of Hollow core}

As the depth of hollow core increases the ultimate load decreases. Also by the increase of core depth deflection increases. It can be observed from Figure 9. So the optimum depth for providing hollow core is just below the neutral axis (here it is $160 \mathrm{~mm}$ ).

\section{Crack Pattern}

At Initial stages of loading, all beams were un-cracked beam. When the applied load reached to the rupture strength of the concrete on specimens, the concrete started to crack. The failure pattern in the all the tested beams was observed as a flexure-shear failure. The beams showed initial cracking in the constant bending moment region and then the cracks patterns in the vertical direction as the load was increased. At about 60 to $70 \%$ of the ultimate load, crack started to appear. All the beams showed the same pattern of failure and the failure modes are shown in Figures 11. 


\section{International Journal of Science and Research (IJSR) \\ ISSN (Online): 2319-7064}

Index Copernicus Value (2013): 6.14 | Impact Factor (2015): 6.391

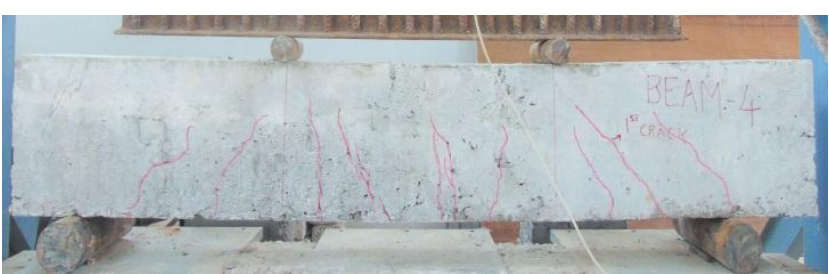

Figure 11: Crack patterns and failure mode of beam specimens

\section{E. Concrete Savingand self-weight reduction}

Concrete is one of the most versatile building material. In construction industries huge wastage in concrete occurs. Material cost is a main component in the total cost of the product varying from 25 to $70 \%$. Therefore, in order to control the cost, it is necessary to pay maximum attention for controlling material cost especially through abnormal losses. It should be made sure that the right quantities of materials are consumed with less wastage. This issue can be minimized by avoiding concrete in the neutral axis without bearing significant strength. Saving of concrete can be efficiently achieved with increase in length and depth of the beam. Therefore it can be effectively utilised during the construction of plinth beams, raft foundation, piers and similar other works.

If we consider the beam in this study, the dimensions are of length $=200 \mathrm{~cm}$, breadth $=20 \mathrm{~cm}$ and depth $=30 \mathrm{~cm}$ with five numbers of PVC pipe having $2.7 \mathrm{~cm}$ radius and length $38 \mathrm{~cm}$. By calculating the volume, we can know the percentage reduction in concrete volume.

Volume of the beam, $\mathrm{V}_{1}=1 \mathrm{bh}=200 \times 20 \times 30=120000 \mathrm{cu} . \mathrm{cm}$

Volume of the pipe, $\mathrm{V}_{2}=\pi \mathrm{r}^{2} 1$

$=5 \times 3.14 \times(2.7)^{2}$ x $38=4349.21$ cu.cm

$\%$ reduction in concrete $=\left[\left(\mathrm{V}_{2}\right) /\left(\mathrm{V}_{1}\right)\right] \times 100$

$=[4349.21 / 120000] \times 100=3.7 \%$

Dead load shall include weight of all structural and architectural components which are permanent in nature. It includes self-weight of the structure. The unit weight of concrete is $25 \mathrm{kN} / \mathrm{m}^{3}$. If we can reduce the volume of concrete then the self-weight of the beam also get reduced.

Weight of $1 \mathrm{~m}^{3}$ concrete $=2500 \mathrm{~kg}$

Considering beam of dimensions:

length $=200 \mathrm{~cm}=2 \mathrm{~m}$

Breadth $=20 \mathrm{~cm}=0.2 \mathrm{~m} ;$ depth $=30 \mathrm{~cm}=0.3 \mathrm{~m}$

Volume of beam, $\mathrm{V}_{1}=\mathrm{lbh}=2 \times 0.2 \times 0.3=0.12 \mathrm{~m}^{3}$

Weight of beam, $\mathrm{W}_{1}=2500 \times 0.12=300 \mathrm{~kg}$

Considering $\mathrm{PVC}$ pipe of dimensions:

radius $=2.7 \mathrm{~cm}=0.027 \mathrm{~m}$;

length $=5 \times 38 \mathrm{~cm}=190 \mathrm{~cm}=1.9 \mathrm{~m}$

Volume of pipe, $\mathrm{V}_{2}=\pi \mathrm{r}^{2} \mathrm{l}=3.14 \mathrm{x}(0.027)^{2} \times 1.9$

$=0.0044 \mathrm{~m}^{3}$.

Weight of concrete saved, $\mathrm{W}_{2}=0.0044 \times 2500$

$=11 \mathrm{~kg}$

Weight of hollow beam $=\mathrm{W}_{1}-\mathrm{W}_{2}=30-11=289 \mathrm{~kg}$

Since we have assumed a small beam, the self-weight reduction is also small. When we assume this for a larger section, the weight reduction will be larger.

\section{F. Labour Reduction}

Labours are one of the major resources in construction industries. Construction labour is most disorganised in India.
Direct labour cost is also a part of the prime cost. It is clearly evident from the study that the total volume saving in concrete is directly proportional to the percentage reduction in labour. Concreting works in construction industry is labour intensive. When the volume of concreting works reduces, the need for labour also get decreased simultaneously, which in turn minimise the production cost.

\section{G. Cost Reduction}

In current days of competition, it is necessary that a business concern should have utmost efficiency and minimum possible wastages and losses to reduce the cost of production. If the cost of inputs increases, then naturally, the cost of the production will go up. The inputs in construction fields include material, machines, labour and other overhead expenses. From the above conducted study we have come to a conclusion that by using reinforced beam with hollow neutral axis, we can save significant amount of concrete without bearing any strength loss. This saving in material cost is more effectively utilised when considering large depth and length of beam or in similar other works, where abnormal lose of concrete occurs. This can be compared to a chain reaction because as the volume of concrete decreases, the material cost reduces which decreases the labour cost, which in turn minimise the construction cost.

\section{H. Applications}

From the evaluation of the results, it was observed that the areas of application of the experimental reinforced beamwith hollow neutral axis include various fields of construction where abnormal losses in concrete occurs. The wastage of concrete can be minimised by adopting this technique of hollow neutral axis of low stress zone without any strength loss. The fields of application are:

- Plinth beams

- Raft foundations

- Piers

- Similar other works

\section{Conclusions}

Based on the experimental study conducted on hollow core RC beams and test result obtained, the following conclusions were drown:

1. Flexural behaviour of reinforced concrete beams with hollow core is similar to that of conventional reinforced concrete beams.

2. Presence of hollow PVC pipe instead of concrete in the low stressed zone has caused an increase of 21 percentage in strength of reinforced concrete beams.

3. The optimum depth of hollow core is $160 \mathrm{~mm}$ from top, iejust below the neutral axis.

4. It has been observed that the replacement of concrete by hollow pipe in reinforced concrete beams does not require any extra labour or time.

5. Economy and reduction of weight in beams depends on the percentage replacement of concrete. The concrete saving will be more effective as the length and depth of the beam increases.

6. Hollow reinforced concrete beams can be used for sustainable and environment friendly construction work as it saves concrete which reduces the emission of carbon dioxide during the production of cement. 


\section{International Journal of Science and Research (IJSR) \\ ISSN (Online): 2319-7064}

Index Copernicus Value (2013): 6.14 | Impact Factor (2015): 6.391

\section{Scope of Future Study}

Further comparative study can be conducted by utilizing different diameters in PVC pipe and their flexural and shear behaviour can be evaluated. Several other parameters can also be tested like impact resistance, abrasion, fatigue resistance, crack propagation, etc. The work can be extended in other mixes and pattern of arrangement of pipes also.

\section{References}

[1] B S Karthik, Dr.H.Eramma\&Madhukaran(2014) "Behavior Of Concrete Grade Variation In Tension And Compression Zones OfRcc Beams" International Journal of Advanced Technology in Engineering and Science, Volume No.02, Issue No. 07, page 2348 - 7550 330.

[2] Dr. T. sekar(2011) -"Studies on strength characteristics on utilization of waste materials as coarseaggregate in concrete"-International Journal of Engineering Science and Technology (IJEST).

[3] G.Murali1， K.R.Jayavelu， N.Jeevitha， M.Rubini and N.R.Saranya (2012) - "Experimental Investigation on Concrete with Partial replacement of Coarse Aggregate "International Journal of Engineering Research and Applications (IJERA) ISSN: 2248-9622 Vol. 2, Issue 2, pp.322-327.

[4] Jain Joy, Rajesh Rajeev (2014) "Effect of Reinforced Concrete Beam with Hollow Neutral Axis" International Journal for Scientific Research \& Development IJSRD, page 341 , Vol. 2, Issue 10

[5] IS 10262-2009 - "Concrete mix proportion guidelines"Bureau of Indian standards - New Delhi.

[6] IS 456-2000 - "Plain and Reinforced concrete code of practice"- Bureau of Indian standards - New Delhi.

[7] Rakesh Patel, S.K. Dubey, K.K. Pathak (2014) "Analysis of infilled beams using method of initial functions and comparison with FEM" Engineering Science and Technology, an International Journal page- 158-164

[8] S.Manikandan, S.Dharmar, S.Robertravi (2015) "Experimental Study on Flexural Behaviour of Reinforced Concrete Hollow Core Sandwich Beams" International Journal of Advance Research In Science And Engineering, IJARSE, page-937,Vol. No.4, Special Issue (01), March 2015 ISSN-2319-8354.

\section{Author Profile}

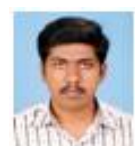

Nibin Varghese is MTech student, Structural Engineering, Sree Buddha College of Engineering. University of Kerala. He did Bachelor of Technology in civil engineering from University of Kerala

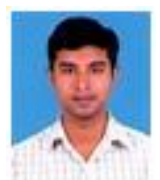

Anup Joy is Assistant Professor, Department of Civil Engineering, Sree Buddha College of Engineering, NediayyathuBunglaw, Choorakodu (P.O), Manakala, Adoor, Kerala. He has done Master of Technology in Structural Engineering from NIT, Calicut and B. Tech in Civil Engineering from TKM

College of Engineering, Kollam 